\title{
LITERATURA, UM PATRIMÔNIO EDUCACIONAL DE REFLEXÃO SOCIAL E POLÍTICA
}

\author{
Doutoranda em Literatura e Práticas Sociais pela Universidade de Brasília. Bolsista pela \\ Fundação de Amparo à Pesquisa e Desenvolvimento Científico do Maranhão - FAPEMA \\ Professora Assistente da Universidade Estadual do Maranhão - UEMA
}

\author{
Prof. Dr. Rogério LIMA, PhD. Universidade de Brasília. Université Rennes 2 - \\ PRIPLAP/ERIMIT. Pesquisador Senior CAPES. PRIPLAP/ERIMIT. \\ Pesquisador Convidado Fondation Kastler. Rede de Ensino e Pesquisa Centro-Oeste - Rede \\ CO3.
}

\section{RESUMO}

Este trabalho se dispõe a refletir sobre a articulação entre a literatura, o sujeito e as habilidades sociopolíticas, pondo em evidência questões como humanização e direito; representação literária e possibilidade do real, a fim de que se possa pensar sobre a importância do conhecimento literário na formação intelectual e humana do cidadão. Nele, advoga-se que a literatura é antes de tudo um patrimônio que agrega em si possibilidades de saberes, sejam eles sociais, políticos, históricos ou culturais. Assim, sob essa perspectiva, direi que a literatura educa, uma vez que o seu tecido se constitui do individual e do coletivo, o que impõe dizer que esse patrimônio, que é a literatura, é feito da matéria da memória, considerando que as imagens representadas no universo da criação literária se dão a partir de elementos internos e externos que circundam e orientam o corpo do escritor.

Palavras-chave: Literatura, patrimônio educacional, humanização, saberes, memória.

\begin{abstract}
This work aims to reflect on the articulation between literature, the subject and sociopolitical skills, highlighting issues such as humanization and law, literary representation and the possibility of reality, so that one can think about the importance of literary knowledge in intellectual and human development of the citizen. In it I will try to show that literature is first and foremost a patrimony that adds in itself possibilities of knowledge, be they social, political, historical or cultural. Thus, from this perspective I will say that literature educates, since its fabric is constituted of the individual and the collective, which forces me to say that this patrimony, which is literature is made of matter of memory, considering that the images represented in the universe of literary creation are based on internal and external elements that surround and guide the body of the writer.
\end{abstract}

Keywords: Literature, educational, heritage, humanization, you know, memory. 
De acordo com o artigo 216 da Constituição Federal, o patrimônio é compreendido entre as formas de expressões, conjuntos urbanos e sítios de valores históricos, paisagístico, turísticos e arqueológicos. Quanto a sua natureza, classificam-se em bens materiais e imateriais. Os materiais são os que agregam conjuntos urbanos e sítios, já os imateriais são aqueles que agregam os saberes, as representações, os conhecimentos, as habilidades e as crenças.

Dentro desse conjunto, a Literatura por ser representativa e agregar em si um saber estético, artístico, histórico, social e político para a formação do indivíduo, encontra-se classificada como um bem cultural imaterial, haja vista que a mesma acha-se ligada ao crescimento intelectual e humano do cidadão, e que resulta de formas de expressão da memória e de modos de criação que proporcionam ao indivíduo a aquisição de saberes.

Embora o texto literário seja de natureza tangível, os conhecimentos advindos da literatura concentram-se em si uma plurissignificação - resultado do seu aspecto subjetivo, etéreo e incorpóreo; fato que não diminui e nem exaure a sua importância e relevância para a formação do cidadão. Entretanto, infelizmente, o patrimônio educacional literário que "busca levar crianças e adultos a um processo ativo de conhecimento, apropriação e valorização da herança cultural" (HORTA et al., 1999), ainda não se encontra a disposição de todos, considerando as grandes disparidades culturais e econômicas que se estabelecem entre as classes sociais, o que termina por permitir que muitos não tenha acesso a esse patrimônio. 
A literatura deve constitui-se como um objeto de reflexão e como um direito na formação humana do indivíduo. Direito que, quando exercido, contribui de forma significativa para a formação da identidade do cidadão, pois, como lembra Antonio Cândido em Vários Escritos (2011), o acesso à literatura enriquece o "exercício da reflexão, a aquisição do saber, o afinamento das emoções, a capacidade de penetrar nos problemas da vida, o senso da beleza, a percepção da complexidade do mundo e dos seres" (CANDIDO, 2011, p. 182).

Assim, se a literatura agrega em si essas capacidades, o conhecimento advindo desta deve ser acessível a toda e a qualquer pessoa, dado que este conhecimento, além de despertar no sujeito a criticidade e a reflexão da história - sociopolítica - local e universal, também desenvolve em nós "uma quota da humanidade, na medida em que nos torna mais compreensíveis e abertos para a natureza, a sociedade, e o semelhante" (CANDIDO, 2011, p. 182).

Falar, então, desse bem educacional corresponde também falar da necessidade universal do conhecimento cultural, intelectual e humano do sujeito. Isto porque, uma vez posta na vida da mulher e do homem, a literatura poderá vir a libertar a consciência crítica dos mesmos, dar forma aos seus sentimentos e ampliar as suas visões de mundo. Logo, esse saber educacional se torna um instrumento de libertação de consciência e de "desmascaramento, pelo fato de focalizar as situações de restrições dos direitos, ou a negação deles, como a miséria e a servidão" (CANDIDO, 2011, p. 188).

O acesso à literatura encontra-se, portanto, na mesma esteira da luta por direitos humanos, que implica em liberdade de ideias, de conviç̧ões e, principalmente, liberdade de 
criticidade. Tal como a liberdade pela luta de direitos, lutar pelo acesso e ampliação do conhecimento literário, é possibilitar condições intelectuais e didáticas de questionar, expor e sugerir por meio da leitura, da representação e da escrita do texto, condições críticas que favoreçam a reflexão e a memória do indivíduo. É nesse sentido que vejo a literatura como um patrimônio educativo, com capacidade de conscientizar e elucidar conhecimentos, pois ainda que seja ela estética e representativa, assume papel essencial na formação política e social do indivíduo.

Como criação artística, o patrimônio literário reúne na escrita do texto elementos educativos que, quando alocados de forma organizada e adequada no interior do texto, tornam-se válidos, do ponto de vista humanitário e político para o leitor e para a compreensão da História, da sociedade, da memória e da identidade, uma vez que a escrita artística não se encontra isolada dos eventos socioculturais.

De acordo com Luckács (2010), quando os discursos socioculturais são trazidos para a escrita do texto literário, e quando estes discursos são tratados com dignidade pelo professor; o leitor poderá vir a vivenciar e a refletir acerca daquilo que é posto na feitura do texto. Penso que isso se chama percepção, conhecimento e consciência política e cidadã de direitos. Direitos que incitam o sujeito a "perceber os contextos histórico-culturais, iniciando pela narrativa de sua vida, suas quedas, seus triunfos e sua realidade" (CANDIDO, 2011, p. 185).

Esse conhecimento literário, advindo da consciência política e cidadã de direitos, coloca-se para o leitor como um instrumento de libertação, tanto na vida individual, como também na história de vida coletiva desse sujeito. Sob esse aspecto, direi que a literatura 
tem um "efeito prático de formar e modificar as condutas e concepções do mundo" (CANDIDO, 2011, p. 30). Posto que o conteúdo que compõe o texto termina reforçando no indivíduo o sentimento de valores humanos, resultado de influências concretas - exercidas por fatores culturais, em uma dada conjectura política, social e histórica.

Ainda que seja difícil discriminar em quantidade e variedade essas influências na criação artística, pode-se dizer que elas se ligam a determinadas estruturas: à memória, a ideologias, a questões de identidade e à vivência sociocultural do autor. Portanto, é compartilhando destes pensamentos teóricos que manifesto: é preponderante o papel da literatura na formação social e política do cidadão, uma vez que o conhecimento que advém da materialidade do texto literário traz para a escrita do mesmo, a representação de particularidades de questões que circundam a obra no ato da sua criação. Isso porque a literatura contextualiza e possibilita aos leitores, sujeitos da recepção, discussões que sustentam ou podem sustentar o universo da criação literária.

Nesse sentido, aqui (re)afirmo a importância desse patrimônio educacional, que contribui para integrar o individuo no mundo estético, histórico e político-social, de forma a contribuir para a totalidade de sua formação humana e para o reconhecimento da memória artística.

\section{PATRIMÔNIO LITERÁRIO: HUMANIZAÇÃO E DIREITO}

Falar de patrimônio literário implica falar de humanização. Pois se a literatura aborda uma universalidade de questionamentos que a inscreve como um espaço para aspirações, argumentações e conscientização. Encontra-se ela ligada às ideias de representação e direitos. Direitos de esclarecer, de socializar, conscientizar, divulgar e de educar. Direitos que 
se consolidam na escrita do texto através dos acontecimentos vivenciados, testemunhados ou imaginados. Daí a necessidade de agregar e difundir na criação literária o diverso, a memória, o politico, o educacional, o social e o patrimonial (GRUMBRECHT, 1998).

Sendo a literatura um direito, ela é antes de tudo humana. Entretanto, o processo de humanização só se concretiza quando o leitor vivencia a representação. Dado que a memória, a identidade e os elementos culturais que se apresentam no interior do texto só adquirem "significado social e literário na medida em que as pessoas correspondem às necessidades coletivas; e estas, agindo, permitem por sua vez, que os indivíduos possam se exprimir" (CANDIDO, 2011, p.35) através da literatura, de maneira a inserirem-se nos interditos da obra. É, pois, esse acontecimento que contribui para que o sujeito liberte-se do caos interior, resultante da desinformação e da falta de oportunidade de leituras, principalmente a literária.

A literatura tem o poder de desvelar e de suscitar questionamentos na mente do leitor, ela agrega em si infinitas possibilidades. Essas possibilidades resultam da aquisição do saber literário, e permite entender e visualizar de forma crítica e consciente o conhecimento posto na feitura da obra, evento que também concorre para a humanização do sujeito. Humanização que implica na alteração recepcional do conteúdo que compõe a obra e que, quando se realiza de forma efetiva, contribui para o desenvolvimento linguístico, cultural e estético do leitor.

Todavia, este desenvolvimento advindo da literatura só acontecerá a partir do entendimento daquilo que se encontra posto na escrita do texto. Tendo em vista que esse 
patrimônio, que é a literatura, abarca uma amplidão de saberes; e quando o leitor consegue apropriar-se desses saberes, o seu conhecimento evolui - resultado do processo de fruição.

A fruição permite a aquisição da compreensão da linguagem do texto. Sendo, portanto, ela que liberta e propõe o conhecimento político e social ao indivíduo. Ora, direi que tal evento acontece na apreensão da linguagem do patrimônio artístico literário, porque o texto comporta em si uma dimensão formadora de razão, de conhecimento intelectual e estético, tendo em conta que.

A literatura assume muitos saberes [...] há um saber histórico, geográfico, social, técnico, botânico, antropológico [...] todas as ciências estão presentes no monumento literário [...] a literatura faz girar os saberes [...] o saber que ela mobiliza nunca é inteiro, nem derradeiro, a literatura não diz alguma coisa, mas que sabe de alguma coisa; ou melhor, que ela sabe algo das coisas - que sabe muito sobre os homens. (BARTHES apud DALVI 2013, p. 19)

Esses saberes e a maneira como eles são apresentados no texto, principalmente o narrativo, é inerente à literatura. Segundo Edward Said, essa competência se faz notória na criação narrativa porque a "constituição de um objeto narrativo, por mais anormal e insólito que seja sempre é um ato social por excelência, e como tal carrega atrás ou dentro de si a autoridade da história e da sociedade" (SAID, 1995, p. 117). Logo, para esse estudioso, a autoridade histórica e social da literatura se legitima no curso do romance.

Sob essa lógica, penso: se a literatura - enquanto patrimônio cultural - granjeia em si uma validação sociocultural e politica, ela deve ser assegurada a todo e a qualquer cidadão, a fim de que se possa amenizar as disparidades intelectuais, promovidas pelo desajuste 
socioeconômico a que nos encontramos submetidos. À vista disso, eis aí a necessidade de disponibilizar o conhecimento literário para a formação individual e integral do indivíduo.

O patrimônio literário deve ser visto como uma necessidade básica, como um bem incompressível $^{1}$ (CANDIDO, 2000) na educação do sujeito. Dado que, tal como a comida, a bebida, a roupa e a habitação, consideradas essenciais para o ser, este patrimônio assume uma função imperiosa na vida do indivíduo. Nesse caso, por que então reservar à literatura um posto secundário, como se fosse algo supérfluo, quando ela ajuda a enriquecer a percepção e a visão de mundo das pessoas?

Se colocarmos o patrimônio educativo literário como algo desnecessário, ou meramente representativo, sem valor nenhum, negaremos ao indivíduo a possibilidade de determinados saberes, que só podem advir da literatura. Saberes que são latentes e "que provêm da organização das emoções e da visão de mundo, considerando que há neles níveis de conhecimento intencional, isto é, planejados pelo autor e conscientemente assimilados pelo receptor" (CANDIDO, 2011, p. 182).

Assim, negar ao sujeito o conhecimento literário implica em negar, também, o direito de ser cidadão. Consequentemente, implica ainda em opor-se ao conhecimento da memória, do direito político, social e cultural; tidos como indispensáveis para uma organização social satisfatória. É preciso que se tenha consciência da relevância da literatura para a memória, história, educação e, principalmente, para a criticidade do sujeito.

\section{O TEXTO LITERÁRIO E A POSSIBILIDADE DO REAL}

\footnotetext{
${ }^{1}$ Segundo Candido (2011), os bens compressíveis são entendidos como aquilo que é supérfluo ao ser humano. Já os bens incompressíveis, compreende aquilo que é essencial para se viver, ou seja, que não pode faltar para o homem, tais como; a comida, a bebida, a moradia, etc.
} 
Sociologicamente, imagino que a feitura da obra se encontra ligada à identidade, à memória e aos outros elementos que circundam a obra - história, sociedade, escritor e leitor; tendo em vista que a escrita é um "sistema simbólico de comunicação inter-humana" (CANDIDO, 2000, p. 31). E como todo processo de comunicação, seja ele literário ou não, pressupõe um comunicante e um comunicando, não tem como a obra desviar-se do leitor, do escritor e da realidade que os circundam.

Ainda sob um olhar sociológico, direi que a literatura na formação do cidadão deve assumir a mesma importância das demais disciplinas curriculares, considerando que o conhecimento que advém da criação literária traz para a escrita do texto a representação de particularidades, de questões pontuais e gerais, que podem abrir expectativas para reflexões teóricas e humanas. Reflexões que possibilitam aos leitores, sujeitos da recepção, discussões que sustentam ou podem sustentar o universo prodigioso da leitura.

A literatura propõe a liberdade a partir da representação, evento que propicia ao leitor despontar para a possibilidade do real. Essa possibilidade é condição sine qua non para suscitar uma transformação no sujeito, isto é, um rompimento com estado de coisas, logo, esta fissura possibilita conhecimento e reflexões de determinados discursos ao indivíduo (LUCKÁCS, 2010).

É a representação do real que faz com que o texto reúna condições para ser argumentado e refletido, de forma a promover uma verticalização do conhecimento. Chamo de verticalização do conhecimento a compreensão dos "ditos e não ditos" (FOCAULT, 2009) que se inscrevem na obra, pois entendo que compreender significa abranger, transcender e 
seguir em frente. Assim, todo aquele conhecimento político, social, histórico e cultural que o leitor apropria-se, por meio do patrimônio educativo literário, cresce e evolui, portanto, é um conhecimento sempre verticalizado.

Esta horizontalidade é consequência da capacidade da linguagem literária, que carrega em si uma forma peculiar de dizer, de ouvir e de se verticalizar. É dessa matéria que o patrimônio literário se vale para conscientizar, para refletir e para formar uma identidade política e educacional; isso se chama direito à cidadania.

Embora representativo, o patrimônio literário possibilita resistência, perspectivas, mudanças e questionamentos que agregam significados diversos (GRUMBRECHT, 1998). Este patrimônio, diferente de outros, usa da arte da escrita para falar da história, da memória e até de si mesmo. O seu discurso abarca uma amplitude de reflexões que favorece uma maior compreensão das coisas; episódio que torna o ensino da literatura essencial nas escolas.

É inegável que o conhecimento pedagógico é constituído por vários outros saberes, e que a realidade vivenciada na escola se encontra hoje, mais do que nunca, orientada por uma cultura tecnológica. Entretanto, é inegável também que a leitura de textos literários se constitui como um bem necessário para a formação ampla do cidadão, considerando que a experiência mediada pelo saber da literatura agrega em si especificidades para o crescimento individual e social do sujeito.

A literatura, como querem muitos, não se resume à grandeza estética. Apesar de ser ela representativa; as suas analogias, a sua subjetividade e a sua carga semântica oferecem um modo diferenciado de penetrar no real, resultado de sua dimensão social e política. Este 
acolhimento diferenciado proporciona ao leitor condições para articular e ressignificar as informações oriundas do texto literário.

Nessa lógica, direi que o patrimônio literário representa vivência, história e vida. E como lembra Gumbrecht (1998), são as vivências - elementos do dia a dia - que faz com que o mesmo ganhe esse status de bem educacional; sendo esta a particularidade diferencial desse patrimônio, que assimila categorias de identidade, memória, gênero e etnia. Categorias que resultam de pedaços de vidas, recordações e experiências: do escritor, do leitor; minha, sua e nossas. Sendo, pois, dessas reminiscências que se constitui o tecido do patrimônio educativo literário.

\section{LITERATURA: VIVÊNCIA E MEMÓRIA}

Compartilho do entendimento de que a criação e o artista se completam a partir da experiência, da alteridade, do político e do social. Compartilho ainda em dizer que "todos os princípios básicos da composição poética não fazem mais do que refletir, concentrando no filtro da síntese literária as formas mais universais e necessárias da própria vida humana" (LUCKÁCS, 2009, p.191). Vida que se encontra atada aos fios da memória - capacidade de conservar, recordar e associar os acontecidos.

A minha reflexão vai, portanto, nessa direção - ver a literatura como um espaço propício para se discutir e possibilitar questões que envolvam o coletivo, o individual e a memória, no universo da criação literária.

Por excelência, a criação literária é o lugar reservado à memória, pois, se o universo da literatura se constitui do individual e do coletivo, a memória é o fio condutor que liga as 
imagens pessoais e sociais (vivenciadas ou imaginadas pelo autor) à representação e à construção do texto literário. Logo, a criação literária se alimenta tanto da representação da imagem-imaginação, como também da representação da imagem-lembrança, considerando que a escrita resulta daquilo que constitui as vivências de quem escreve.

Vivência é tudo aquilo que experimentamos ou testemunhamos, e que o corpo traz para área da presença, ela resulta da marca da anterioridade, aquela que implica os eixos temporais do antes e o do depois (BERGSON, 1999). Desse modo, não há criação literária sem a marca do vivido, uma vez que ele se sobrepõe na vida do sujeito que cria, imagina, recorda e narra.

Conforme Paul Ricouer (2007), o narrar pertence à memória, esta por primazia se vale do vivido. O termo vivido remete a experimentado, fato que me impõe dizer que na criação literária o escritor é o sujeito da experiência, e que mesmo sendo os referentes desta criação imaginados, resultam eles da vivência daquele que cria. Deste modo, a escrita artística advém da matéria do recordado.

Uma vez sendo vivência, a memória resulta de um trabalho coletivo (HALBACHS, 2004), tendo em conta que ela preserva em si uma ideia de conjunto: o individual, o social, o político, o cultural, e a relação com o outro e com o mundo. Intuo mencionar que esse mundo é a vivência do escritor, que se constitui de experiências externas e internas; experiências que têm como centro o eu - no mundo, dado que o conjunto obra e criador pressupõe o termo mundanidade ${ }^{2}$.

\footnotetext{
2 Termo usado pelo filosofo Paul Ricoeur (2007) para explicar como a fenomenologia da memória encontra-se ligado ao corpo, e como o corpo e as recordações encontram-se ligados ao mundo.
} 
A mundanidade se impõe na escrita literária, de maneira a fazer com que o eu artístico transcenda os limites do mundo puramente individual, fato que faz da literatura um evento social. Essa transcendência, consequentemente, responde pela dimensão dialética do real, que concentra em si uma totalidade efetiva dos acontecimentos sociais.

Assim sendo, o escritor ao construir o texto revisita o individual, o social, o político, o cultural e o histórico; elementos que ajudam aflorar a memória, e que resultam de um trabalho de alteridade, uma vez que são de particularidades que se forma o trabalho da anamnese. Eis aí o espaço da literatura (BLANCHOT, 1987), tomado como uso específico para situar a história dos indivíduos, das coisas e do mundo.

Imagino que o vocábulo mundo representa uma totalidade, o que sugere uma universalidade de imagens, sujeitos, pensamentos e criação. Toda essa universalidade se vale da linguagem, pois é ela que media a relação do homem com o cosmo, assim memória e linguagem equivalem-se, dado que tudo que está na memória do criador é trazido para área da presença pela linguagem. Assim, o que se põe na feitura do texto são reminiscências, isto é, são imagens vividas, testemunhadas e imaginadas - que se constroem a partir da vivência daquele que cria.

O processo da criação literária é dinâmico, de maneira a fazer com que a representação aflore ou como imagem-imaginação ou como memória. A partir do que viveu, viu ou ouviu; o escritor traz as imagens para serem representadas no texto, e de modo criativo ele articula e faz desabrochá-las na sua criação artística. 
Na criação literária, o objeto desejado e pensado recorre à criatividade artística do criador. A representação desse objeto encena uma lembrança-imagem, considerando que o artista vai buscar a imagem do objeto (imaginado ou real) nos rastros de uma vivência, testemunho e experiência; tencionando que o corpo de quem cria ou recorda não é isolado da realidade que circunda a composição da obra.

Logo, a matéria da criação literária é sempre o espaço vivido, à vista que a “corporeidade é constante e convive no interior da vida psicológica, com a percepção do meio físico e social que circunda o sujeito" (BOSI apud BERGSON, 1994, p. 44) e a obra. O que sugere pensar também que os elementos que cerca o corpo do artista se constituem como uma "forma embrionária e latente" (LUCKÁCS, 2010, p. 192) para a criação da literatura.

A dialogicidade da obra é sempre com a memória, pois, tanto o homem como a lembrança pertence ao mundo da experiência. Logo, no patrimônio literário a memória tem um lugar assegurado, tanto na mediação das imagens que forma o saber social e político do texto artístico, como também no conjunto das sensações: os cheiros, as cores, as fantasias, os eventos transcorridos, os espaços, o belo, o feio, o sagrado, o mito - matérias primas da criação literária.

Portanto, na literatura, a representação das imagens alocadas no texto constitui lembranças de um corpo que viveu, sonhou ou imaginou; assim resultam elas da experiência de quem escreve. A imagem se impõe na escrita literária como uma espécie de reconhecimento que aflora da percepção do sujeito criador. Dessa maneira, digo que tudo aquilo que forma o tecido literário constitui autênticas ressureições. Ressureição no qual se 
combina processo corporal, literatura, vivência e memória, assim é, portanto, do entrecruzamento deste revivescimento que resulta o tecido que forma e estabelece o patrimônio educacional literário.

\section{REFERÊNCIAS}

BOSI, Ecléa. Memória e sociedade: Lembranças de velhos. 3ạ ed. São Paulo: Companhia das Letras, 1994.

CANDIDO, Antonio. "O direito à literatura". In: Vários Escritos. Rio de Janeiro: Ouro Sobre Azul. 2011.

Literatura e sociedade. 11aㅡ ed. Rio de Janeiro: Ouro sobre azul. 2000.

DALVI, Maria Amélia. "Leitura de literatura na escola". Aula. BARTHES, Roland. São Paulo: Parábola, 2013 (1979).

FOUCAULT, Michel. Arqueologia do Saber. 4ạ ed. Rio de Janeiro: Jorge Zahar, 2009.

GUMBRECHT, Hans Ulrich. "Patologias no Sistema da Literatura". In: Corpo e Forma. Ensaios para uma Crítica Não-Hermenêutica. Organizador João Cézar de Castro Rocha. Rio de Janeiro: Eduerj. 1998.

HALBWACHS, Maurice. A memória coletiva. Trad. Laís Teles Benoir. São Paulo: Centauro, 2004.

HENRI, Bergson. Matéria e memória: ensaios sobre a relação do corpo com o espírito. Tradução Paulo Neves. 2a ed. São Paulo: Martins, 1999.

HORTA, Maria de Lourdes Parreiras. GRUNBERG, Evelina. Monteiro, Adriane Queiroz. Guia básico de educação patrimonial. Brasília: IPHAN, 1999.

LUCKÁCS, György. Marxismo e teoria da literatura. 2a ed. São Paulo: Expressão Popular, 2010.

Georg. Arte e sociedade. Escritos estéticos 1932-1967. Rio de Janeiro: Editora UJRJ, 2009.

MAURICE, Blanchot. O espaço literário. Trad. Álvaro Cabral. Rio de Janeiro: Editora Rocco, 1987.

PAUL, Ricoeur, A memória, história e esquecimento. Campinas. São Paulo: Editora Unicamp, 2007.

SAID, Edward W. Cultura e Imperialismo. Trad. Denise Bottman. São Paulo: Companhia das Letras, 1995. 
Artigo recebido em: $\mathbf{3 1}$ de maio de 2018. Artigo aprovado em: 25 de agosto de 2018. 